\title{
Body, Telephone, Voice: Black Christmas (1974) and Monstrous Cinema
}

\author{
Morten Feldtfos Thomsen \\ Karlstad University (Sweden) \\ E-mail: mortfeth@kau.se
}

\begin{abstract}
This article investigates the role of the telephone as both an engine of suspense and a metaphorical double of cinema in Black Christmas directed by Bob Clark (1974). Employing Michel Chion's concept of acousmatic voice, the article first explores the role of the telephone in creating both narrative suspense and diegetic cohesion. It then investigates how the film implicitly establishes a pattern of resemblance between the telephonic and cinematic mediums centred on their capacities for diffusion and disembodiment. Finally, the article explores the meta-cinematic implications of its preceding findings, arguing that the fears and anxieties associated with the telephone in Black Christmas ultimately concern cinema itself and its possible cultural impact. Although it attempts to enforce certain categories of knowledge and identity, Black Christmas ultimately engages with cinema's capacity for subverting rather than enforcing ideology.
\end{abstract}

Keywords: Black Christmas, slasher cinema, telephone, technology, acousmatic voice.

\section{Introduction}

Horror cinema is riddled with threatening telephone calls. In the Italian giallo, for instance, it is an often-used medial motif, and in countless US productions - such as I Saw What You Did (William Castle, 1965), When a Stranger Calls (Fred Walton, 1979), or Wes Craven's Scream films (1996, 1997, 2000, 2011) - it is a central catalyst of narrative momentum. At its most basic, the purpose of the motif is simply to create suspense by setting the stage for an often unknown and potentially dangerous individual lurking somewhere outside the frame of the cinematic image. ${ }^{1}$ In the 1974 Canadian teen slasher Black Christmas, however,

1 On the history of the motif not only in horror cinema, but in the suspense and noir genres, see Debatin and Wullf (1991), Gunning (1991, 2004), Schantz (2003, 2008), Bohnenkamp (2014), 
the motif also reflects anxieties concerning the possible erosion of established categories of knowledge and identity, particularly as it relates to a range of overlapping and ideologically charged dualisms dominant in Western culture: self/other, male/female, human/machine, reality/illusion.

I will return to these dualisms at various points throughout the following analysis. My primary focus, however, is on the meta-aesthetic - or meta-cinematic - implications and impulses associated with the telephonic motif. Not only does the motif function as a site for the collapse of established cultural boundaries and the production of monstrous difference, but it also works as a double of, or standin for, the cinematic medium. ${ }^{2}$ Consequently, the film implicitly situates cinema itself within the realm of the monstrous.

Building primarily on Michel Chion's concept of acousmatic voice - that is, a voice, which is heard, but whose cause or origin is not visible within the frame of the cinematic image - this article argues that the telephonic motif in Black Christmas metaphorically articulates a highly anxious and ambivalent understanding of cinema and its possible cultural impact. On the one hand, Black Christmas implicitly understands cinema as a device for the reproduction of ideology, that is, a representational machinery employed to enforce certain hierarchies of social and political power as well as the categories of knowledge and identity that underpin them. On the other hand, it also dwells anxiously upon the capacity of cinema to create modes of thought and experience that subvert such processes, thereby undermining the representational strategies through which ideology promulgates. Even as a vehicle for the reproduction of ideology, to put it another way, Black Christmas anxiously engages with its own capacity for subverting the very system of power that it attempts to enforce. In consequence, the telephonic motif in Black Christmas ultimately concerns the monstrous possibilities and potentials of cinema itself.

\section{Vision and Voice}

Black Christmas tells the story of a mysterious killer stalking a group of sorority sisters during the Christmas holidays. Hiding in the attic of their sorority house, the

Wagner (2014) and Boillat (2015). Bruhm (2011) also explores the motif specifically in relation to modern cell phones. He briefly discusses Black Christmas but focuses primarily on the 2006 remake, Black X-mas (Morgan 2006), and other more recent examples.

2 To be clear, my use of the concept of "the cinematic medium" does not rely on an essentialist or reductionist position. I use it synonymously with "cinema" to refer broadly to the projection and recording of moving images. 
killer uses a second telephone line to call and harass them while simultaneously murdering them one by one. ${ }^{3}$ Throughout the film, the killer is kept off-screen, and one of the key formal strategies through which this is accomplished is subjective camerawork. Indeed, Black Christmas is often cited as one of the first horror films to make extensive use of what has since become a cliché of the slasher subgenre, namely the point-of-view shot. ${ }^{4}$ From the beginning, this technique is established as a central stylistic device, as the opening wide-shot of a Christmas decorated sorority house is followed by a cut to the killer's point of view as he scales and enters the house via an attic window. Throughout the film, the viewer is repeatedly returned to the killer's point of view as he sneaks around the house unseen, stalking and observing his soon-to-be victims. These point-of-view shots are a central engine of suspense, providing the viewer with knowledge of the killer's proximity to the unknowing protagonists. Furthermore, the distinction between subjective and objective camerawork is often blurred, making the viewer unsure of which shots belong to the killer and which do not. This ambivalence imbues much of the camerawork in the film with a sense of uncertainty and tension. Another feature of the point-of-view shot, of course, is that it obscures the killer's identity by excluding him from the image and confining him to a vaguely defined space outside of the frame. We see his seeing, but he never becomes the object of ours. While the point-of-view shot thus strongly indicates presence, it does not provide the kind of visualization that would place the killer under the control of the camera's gaze, and establishes a notable tension between presence and absence, on-screen and off-screen. ${ }^{5}$

Within this particular narrative and stylistic framework, the telephone plays a significant role, primarily by working as a vehicle for the killer's acousmatic voice. Coined by Michel Chion, the concept of acousmatic voice refers to a voice which is heard, but whose point of origin - meaning the person to whom the voice belongs - does not appear on-screen. Such voices are a staple of horror cinema, and here help to produce a range of effects that work in tandem with the film's camerawork. One key effect of the killer's acousmatic voice, such as

3 The film builds on a well-known telephonic narrative, namely the urban legend known as The Babysitter and the Man Upstairs, which concerns a babysitter harassed via telephone by a murderer who turns out to be hiding upstairs (Danielson 1996). As I see it, the technique comes less from Hollywood's experiments with the subjective camera [...] than it does from the pioneering Italian gialli of Mario Bava and Dario Argento" (Hart 2020, 91).

5 My analysis of the use of subjective camerawork in Black Christmas is indebted to Hart (2020), whose work, in turn, builds on extensive previous research into the use of point-of-view in the slasher genre done by scholars such as Vera Dika (1990) and Carol Clover (1992). 
established via the telephonic motif, is the strong blurring of the distinction between the film's on-screen and off-screen spaces, emphasizing the killer's possible transgression of the boundary between them, i.e. the frame of the cinematic image. Functioning as a signifier of the killer, the acousmatic voice plays a key role in establishing narrative suspense, simultaneously signalling both the absence and the presence of the killer. In so doing, it allows the character behind the voice to become functionally ubiquitous. Since the viewer does not know where the killer is, he might in principle be anywhere, see anything, know and do anything (Chion 1999, 24). Both the subjective camerawork and the acousmatic voice, thus, allow the killer to become a quasi-embodied or even disembodied entity, simultaneously on-screen and off-screen, present and absent, everywhere and nowhere.

Further emphasizing this sense of uncertainty is the fact that much of the film's narrative space is structured around the telephone, thereby limiting the viewer's respite from the threat it poses. An illustrative example of this strategy is the depiction of the killer's first telephone call. As the film's protagonist, Jess answers the downstairs telephone, the camera remains focused on her as she calls out to the other sorority sisters. While they subsequently gather around the telephone, the camera remains completely static, as if paralysed by the voice on the telephone. There are no reaction shots of the sorority sisters to Jess's outcry nor any cuts to their individual advances towards her. All the viewer sees is a static medium wide-shot of Jess holding the telephone as the other protagonists successively enter the frame. Everything here revolves around the telephone and the acousmatic voice emanating from it, calling both the narrative space of the film and the characters within that space into order.

Furthermore, the telephone often works as a visual anchoring point. On numerous occasions, shots begin with a close-up of the telephone and then pan over to the action, establishing in visual terms a sense of continuity between the apparently passive object and the active subjects surrounding it. In other instances, the telephone is placed within the frame, but near its edges or in the background to suggest its presence even in cases where it does not have any direct narrative impact. Such compositional strategies suggest continuity between technological environment and acting bodies as the telephone becomes a potentially active body within the frame, threatening to collapse the distinction between passive background and active foreground that often governs mainstream cinema (Adams 2011). Throughout Black Christmas, therefore, the telephone is almost always there; a seemingly innocuous everyday household object transformed into an 
uncanny presence that may at any instance signal the intrusion of horror into the supposedly safe world of the main protagonists.

Another example of the telephone's terrible power is its role in the film's penultimate narrative climax, as the police finally manage to trace the killer's calls back to the sorority house. Consisting entirely of crosscuts between four different spatial positions, the sequence works as a veritable chase scene. At the sorority house, Jess listens to the killer's incoherent ramblings on the living room telephone, attempting to keep him on the line long enough for the trace to work. A medium close-up showing Jess on the telephone is intercut with shots of the killer's point-of-view in an upstairs bedroom as he speaks frantically into the telephone mouthpiece. Added to these shots are shots of the police listening in on the call at the downtown police station, as well as shots of a technician running through rows of exchange terminals at the telephone company central in order to physically trace the call back to its originating terminal. Throughout the sequence, the killer's voice functions as a reference point, linking the various actions depicted at each location into a meaningful chain of connected events. As a result, it works as a central cohesive force of cinematic montage, placing itself at the centre of the film's narrative unfoldment. This is noteworthy because the telephonic motif has played an important role in the history of narrative cinema, particularly in relation to the emergence of crosscutting (or parallel editing). ${ }^{6}$ Tom Gunning, for instance, singles out the telephonic narrative in D. W. Griffith's The Lonely Villa (1909) as the locus classicus of crosscutting in narrative cinema, pointing out that cinema's interest in the telephone predates the advent of sound (1991, 188). Also referencing Griffith's work, Chion similarly notes that although we might commonly associate stories built around telephones with sound cinema, "the telephone, and everything having to do with the circulation of sounds and voices, was as interesting to silent film as it was a challenge to depict" (1999, 62-63). Going back all the way to the silent era, then, we find a telling interaction between the telephonic motif and the use of crosscutting as filmmakers used the telephone to make the plasticity of cinematic space and time more easily legible to viewers. The collapse of time and space made possible by the telephone-speaking now to someone located elsewhere - became an interpretive blueprint for the manipulation of time and space as established in narrative cinema. Consequently, the telephonic motif became a way for filmmakers to "naturalize film's power

$6 \quad$ For more on this subject, see Debatin and Wullf (1991), Gunning (1991, 2004), and Olsson (2004). Chion also touches briefly upon this specific subject, noting that "the phone scene encourages parallel editing" (Chion 1999, 63). 
to move through space and time" (Gunning 1991, 187). In Black Christmas, the telephone takes on a similar role, effectively making the killer's voice the guarantor of diegetic cohesion and narrative unfoldment and thus establishing the telephone's terrible power as the film's central organizing principle.

\section{Disembodiment and Difussion}

In Black Christmas, therefore, the telephone is a somewhat paradoxical object, simultaneously attractive and repulsive in both stylistic and narrative terms. Most notably, however, much of the film's tension derives from the ways in which its stylistic strategies relate to the figure of the killer - in particular the way in which subjective camerawork and acousmatic sound separate vision and voice from the body in which they are situated, thereby establishing the killer as a diffuse, disembodied presence both within the film's diegetic space and upon the representational surface of the screen. Even if the voice enables diegetic cohesion, it simultaneously works as a cipher for the ostensibly dangerous processes of technological disembodiment and diffusion. Because of this, the film's central narrative trajectory focuses on returning vision and voice to the body from which they originate, thereby divesting the killer of the power bestowed upon him by technological disembodiment. This search for coherence and unity is a significant feature of many slasher films. As Vera Dika (1990) notes, a key step in defeating the killer in many slasher films is for him or her to become visible within the frame of the image, not only to the on-screen characters but to the viewer as well. Although not discussing the slasher film specifically, Chion makes a similar argument regarding acousmatic voices more generally, noting that in order to divest the acousmatic voice of its power, the viewer needs to see the speaking mouth from which the voice originates, that is, "for the person speaking to inscribe his or her body inside the frame" $(1999,27)$. The end-point of this process of de-acousmatization is for the speaking mouth to become visible, allowing the viewer to identify, locate and re-embody the voice. Without binding the voice to a specific body via the explicit on-screen depiction of the speaking mouth, this process will remain incomplete, and the voice will retain its powers (Chion 1999, 28). Hence, slasher films featuring subjective camerawork and/or acousmatic voices often work towards returning both vision and voice to the body from which the representational machinery of the film itself has often separated them in order to create suspense.

Placing this search for coherence front and centre in both narrative and stylistic terms, Black Christmas in turn codes the processes of diffusion and 
disembodiment as not only highly suspect, but even dangerous. One obvious example of the danger posed by diffusion and disembodiment is the role of the telephone in the death of Jess's boyfriend, Peter. Lurking upstairs, the killer overhears Jess and Peter arguing downstairs. During a later telephone call with Jess, the killer repeats certain phrases uttered by Peter during the argument, causing Jess to suspect that Peter may be the killer. This suspicion plays a central role later, when Jess - believing Peter to be the killer - batters him to death with a fire poker. Rather than being a tool for communication, the telephone in this way becomes a dangerous device of miscommunication and confusion. In Black Christmas therefore, the telephone's dissociation of voice from body is ultimately a deadly danger, because it allows identities to become unstable and detached from any definite or stable point of reference. By allowing the voice to float free, no longer bound to a specific physical body, the telephone functions as a site for the unmooring of fixed identities. In semiotic terms, the telephone uncouples signifier and signified, thereby establishing the killer as the monstrous dramatization of a free-floating signifier.

The killer's monstrously disembodied voice, furthermore, transgresses the spatial and temporal boundaries of the film's diegesis. Indeed, in one key moment it is established as the film's one and only trans-diegetic phenomenon. When first we hear the killer's voice separate from the telephone, he is quietly singing a lullaby to his first victim in the sorority house attic. Initially his voice is low and intimate, as would plausibly be the case given the particular acoustic environment presented on-screen. After a few lines of singing, however, a notable amount of echo is added to his voice, providing it with an almost otherworldly quality, as if it no longer resonates just within the small attic-space we see on-screen, but rather within a larger off-screen space, functionally beyond the diegesis itself. In moving, thus, into an extra-diegetical space, somewhere between the film's inside and outside, the killer's voice becomes functionally supernatural, since it no longer abides by the spatial rules that otherwise govern the film's diegetic space. Moreover, the addition of echo is coupled with a slow cross-dissolve to an exterior shot of the college campus square some time the next day. This particular stylistic choice further foregrounds the killer's diffusion by suggesting that his presence goes beyond the specific spatial location from which the voice originates to pervade not just the entire diegesis but even beyond it. He is simultaneously here, there and everywhere.

To be clear, this is not a case of the sound design producing a rupture of diegetic coherence or viewer integration in order to establish a kind of Brechtian 
sense of estrangement or detachment. Rather, it is a subtle gesture towards the possibility of such a rupture. Because it is never realized, however, the effect is one not of estrangement or distance but rather of unease and anxiety. While it gestures towards the killer as an entity somehow in violation of the film's representational paradigm - which remains solidly realist - it never establishes him as supernatural in actual terms. Black Christmas, in other words, does not deal with the supernatural per se. Instead, it establishes a sense of tension between the ostensibly realist narrative and the "unreal" or "supernatural" representational strategies through which that narrative unfolds, specifically in relation to depictions of the killer. In other words, the killer is dangerous not only because he kills, but also because he implicitly constitutes a kind of representational anomaly that threatens to collapse the film's diegetic integrity and narrative unfoldment.

\section{Patterns of Resemblance}

Beyond establishing the killer as a quasi-supernatural entity, the most important aspect of the scene described above is that it suggests the ways in which Black Christmas implicates cinema itself in the dangerous processes of diffusion and disembodiment. It does so by mirroring (and enhancing) the telephonic disembodiment of the killer with cinematic effects, thereby metaphorically establishing a link between the two. Notably, the particular use of sound evident in the scene foregrounds how the film establishes the killer as a diffuse and disembodied entity not only intra-diegetically, from the perspective of the onscreen protagonists, but also extra-diegetically, from the perspective of the viewer. As the echoes of the killer's mysterious voice reach out beyond the film's diegetic space, we experience his presence much in the same way as the protagonists, that is, as a being or entity which does not adhere to the established spatial and temporal rules that otherwise govern the film. A central difference, however, is that his apparent ubiquity from our perspective results not from telephonic disembodiment but rather from cinematic. As a result, the scene establishes a pattern of resemblance between the telephonic and the cinematic mediums, linking them together as devices of diffusion and disembodiment. This pattern of resemblance is suggested in other ways as well, perhaps most notably via the interaction of acousmatic sound and subjective camerawork, specifically the ways in which the film's subjective camerawork mirrors the processes of diffusion and disembodiment associated with the telephonic motif. The ways in which the use of 
subjective camerawork establishes the camera itself as a dangerous presence within the film's diegetic space constitute a key element in this regard. Because point of view shots precede more or less all of the killer's acts of violence in the film, the disembodiment afforded to the killer via the camera is deemed equally dangerous to that of the telephone's - if not even more so. As Hart notes, the point-of-view shot found in films such as Black Christmas "abstracts the look, removing it from reference to a familiar or concrete character who is doing the looking. It presents the act of looking to the audience and should [...] be understood as a depiction of that look. That is, the look itself is just as much the object of the camera's gaze as are the victims-to-be who appear on camera" $(2020,98)$. While the point-of-view shot might align the viewer tangentially with intra-diegetic characters, it more dominantly aligns the viewer with the camera itself. Furthermore, because pointof-view signals the possibility of an attack, it implicitly renders the camera itself dangerous, not in narrative terms, of course; but in functional terms, since without the presence of the camera, there would be no threat. As noted earlier, this threat is specifically established as a result of diffusion and disembodiment, since these are the very processes that allow the threat to materialize both metaphorically and literally. In this way, the interaction of the telephonic motif and the subjective camerawork foregrounds the metaphorical relationship between telephone and cinema by establishing a pattern of resemblance centred on their capacities for disembodiment and diffusion.

This further entails that while the distinction between the killer and the telephone collapses at the intra-diegetic level, the distinction between the killer and the camera similarly collapses at the extra-diegetic level. From both perspectives, therefore, the killer becomes inseparable from the medium through which he is literally made present. Within this context, the previously described narrative trajectory of de-acousmatization can be understood as an attempt to establish a clear boundary between subject and technology by grounding the killer's acousmatic voice within a specific physical body, which can then be made subject to the control of law. Black Christmas's narrative focus on dispelling the dangerous forces of technological diffusion and disembodiment thus metaphorically articulates a highly anxious relationship to cinema, which itself becomes a dangerous engine of such forces.

Hence, it is particularly significant that the killer is never made fully visually present to the viewer, and thus consistently resists de-acousmatization. As previously mentioned, the use of subjective camerawork plays a key part in this, but even when not presented via point-of-view, shots of the killer are carefully 
framed and composed in ways that allow him to escape the camera's gaze. Throughout the film, therefore, he is never seen speaking and appears to the viewer only in dissociated fragments. Even in the two brief moments where we actually see the killer's face, careful framing ensures that only one of his eyes is actually visible. Presenting the killer as a constantly shifting patchwork or medial assemblage, rather than a cohesive subject, the film allows neither the camera, nor the viewer any sense of clarity or control.

Consequently, Black Christmas offers no escape from the dangerous processes of technological diffusion and disembodiment associated with both with the telephonic and cinematic mediums. Instead, it implicitly suggests a profound and highly dangerous interpenetration of human subjectivity and technology a process of which the telephonic and cinematic mediums become monstrous engines and the killer an equally monstrous cipher. Highly suggestive of this interpenetration is the way in which the film's sound design foregrounds the non-verbal elements of the killer's voice, that is, the various sonic elements that surround, but are not part of speech proper. As Conner $(2000,380)$ notes, the telephone does not merely transmit articulate sounds but also the "accidental noise of the voice, the sonorous excrescences which are incidental to the message, but nevertheless [make] up a voice's individuating timbre." When listening to a telephonic voice, we hear "the pants, gasps, and hisses, the clicks, pops, and percussions, of the breath sounding amid its originating body and amid the sensitive body of the telephone apparatus" (Conner 2000, 380). In other words, the telephone does not neutrally transmit the human voice, but foregrounds certain elements as well as ads others to it by way of the interaction between the speaking mouth and the telephone itself. By emphasizing such features, the sound design foregrounds the hybrid characteristics of the killer's voice, establishing it as neither purely human nor purely mechanical, but rather a combination of the two. In some of the scenes, even where we hear the killer's voice separate from the telephone - like when he whispers incessantly before killing one victim, or when he screams wildly while attempting to break down a door -, it retains many of the sonorous characteristics of his telephonic voice. Throughout the film, the killer's voice thus remains implicitly telephonic even in instances when he is not heard speaking through the telephone; and because he is never actually seen speaking, of course, he remains disembodied as well. The implicit effect of this is to establish him as a hybrid entity who never really exists outside mediation, so to speak, but is always enmeshed by it; present only as a kind of continuously displaced medial assemblage, rather than a coherent, unified subject. 


\section{Reproductions of Ideology}

The telephonic motif in Black Christmas thus reflects deep-seated cultural anxieties concerning technology and its possible impact upon human identity and subjectivity. Indeed, the motif is central to the film's implicit idealization of the cohesive and ultimately autonomous humanist subject, dominant - though not hegemonic - throughout much of Western culture going back at least to Kant's concept of the transcendental subject and possibly to Descartes's cogito ergo sum. Employing the telephone as metaphor for cinema, furthermore, Black Christmas implicitly involves cinema itself in the dangerous processes of technological diffusion and disembodiment of the subject, and engages with the potential of cinema to function as a site for the production of monstrous difference.

In order to gain a fuller understanding of the role this monstrous potential plays in the film, however, it is necessary to investigate further the ways in which the dangerous collapse of distinction between subject and technology is mirrored by the collapse of several other identity categories. It is worth noting, for instance, that the unusual character of the killer's voice is foregrounded from the very first telephone call, as our attention is drawn to its fragmented and disjointed form. Following the killer's outburst of excited slurping, groaning and screaming, one of the sorority sisters worriedly asks if it could really be just one person speaking. At a later point, Jess notes: "It was weird. Some man screaming. Then a woman wailing." Throughout the film, the killer's voice is presented as a patchwork of different voices among which his "true" voice remains elusive. While ostensibly presented as male, he oscillates between female and male as well as adult and child voices. Moreover, his voice is reminiscent of various animal or animal-like sounds. The resulting identity fluidity is clearly coded as dangerously pathological, with the voice functioning as the signifier of a monstrously unstable and incoherent psyche, liable to violate the norms and morals of the reigning social order.

In Black Christmas, therefore, the telephonic acousmatic voice of the killer serves as a way of dramatizing the dangers of any form of identity fluidity that violates established identity categories. Within this context, the previously described process of de-acousmatization - as well as the film's implicit fight against forces of technological diffusion and disembodiment in general - can be understood not only as the attempt to separate the voice from the technologies through which it promulgates, but also to return it to a stable and acceptable gender identity by situating it within a safely gendered body. Because we never see the killer, however, this attempt fails, and the killer remains a threat to the 
systems of meaning and knowledge that underpin traditional gender categories.

That a film released in the wake of second wave feminism would exhibit concerns and anxieties regarding the destabilization of established gender identities is hardly surprising. Indeed, Black Christmas conforms quite nicely to Klaus Riser's argument that while the slasher film in general seems to deviate from more traditional gender norms found in Hollywood cinema, it nonetheless conforms to that cinema's "patriarchal signification" (Riser 2001, 370). This tension between progressive and conservative impulses is particularly interesting in relation to Black Christmas because the film is overtly feminist, seemingly championing women's rights in the face of abusive patriarchal authority. It does so not only by focusing on a group of young female protagonists, but also through the inclusion of an abortion subplot, which finds protagonist Jess rejecting her boyfriend's controlling and abusive behaviour and asserting her right to selfdetermination. As Richard Nowell $(2011,68-78)$ has pointed out, this particular political bent was intended by the film's producers to attract progressive females following the surge of second wave feminism in the early 1970s, and, thus, was part of a calculated effort to make the film as appealing as possible to that specific demographic group. Its overt feminism aside, the film remains fundamentally opposed to any destabilization or transgression of established gender categories or norms, clearly coding such transgressions as dangerously pathological. This is done not only via the figure of the killer, but also through several of the film's character portrayals, most notably the characters of Barb and Mrs. Mac, who both display traits that clearly violate the norms of traditional gender behaviour, i.e. the association of women with femininity and men with masculinity. In both cases, their transgressions are clearly coded as socially problematic: while Barb's seeming disregard for various gendered rules of decorum and behaviour is explicitly presented as the result of a dysfunctional relationship with her mother, Mrs. Mac's is presented as the result of rampant alcoholism.

The film's reproduction of certain norms of gendered behaviour is also evident in the portrayal of its male protagonists, who are hardly representatives of ideal masculinity as conceptualized under patriarchal capitalism. Clare's father, for instance, spends most of the film confused, scared, and incapable of helping or taking action. He comes across more as a form of comic relief than a commandeering figure of authority. Another figure of male ineptitude is Sergeant Nash, who fails to help Jess and her friends at every turn. In general, the police are of little help, and are either incompetent or dangerous to the female protagonists. Even the only officer who seems capable of helping, Lieutenant Fuller, ultimately 
fails when at the film's end he leaves an unconscious Jess alone in the sorority house with the undetected killer still inside.

Even so, the film is hardly anti-patriarchal in any meaningful sense of the word. It seems relatively clear that what the film disparages is not patriarchal authority as such, but rather a particular model of inept and impotent masculinity. It calls not for an end to patriarchy, but for a reformation of the model of masculinity underpinning it. Simultaneously, it also presents a model of acceptable femininity, which is self-determinant only to the extent that it remains dependent upon patriarchal power. As the film ends with this ideal feminist subject abandoned by incompetent masculinity to die at the hands of the queer monster, the film implicitly calls upon the ostensibly male viewer to articulate and enact an improved masculinity, that is, to save the damsel in distress and thus reassert the legitimacy of patriarchal authority. The implied female viewer, on the other hand, is left pondering the risks of rejecting patriarchal power and the safety it hypothetically offers. Subjecting the viewer to a clear case of ideological interpellation, the film thus implicitly attempts to enforce extant hierarchies of social and political power by fiercely patrolling the borders of those gendered identity categories upon which such hierarchies rest.

Even if Black Christmas contains certain elements which might reasonably be described as socially and politically progressive for its time, these elements are better understood within a larger narrative framework, which is marked by decidedly more conservative and even reactionary tendencies.

\section{Monstrous Cinema}

As this brief exploration of the film's gender politics suggests, Black Christmas clearly works as a device for the reproduction of ideology, attempting to safeguard and enforce a range of cultural categories and boundaries, perhaps most overtly those relating to gender and sex. Even if the representational machinery of cinema is, thus, used as a device of ideological interpellation, there is within the film an anxious undercurrent, too, which is concerned with the potential of cinema to subvert and possibly undermine the forces that allow for ideological interpellation in the first place. Black Christmas thus works as an engine for the reproduction of ideology, while implicitly engaging simultaneously with the monstrous potential of cinema to subvert the very ideology it attempts to assert.

In this regard, the telephone remains a focal point, working as a double of or stand-in for cinema. As noted earlier, the telephonic motif is a central generative 
and organizing force within the film, serving as a focal point of not only narrative unfolding, but also diegetic cohesion. It is, in other words, a central cog in the film's representational machinery and therefore, ultimately, the source of the film's capacity for ideological interpellation. In the meantime, however, it is also clearly linked to the dangerous processes of diffusion and disembodiment. These powers are a threat to the film's implicit ideological project - i.e. the enforcement of certain categories of identity and knowledge - since they allow precisely for the destabilization of identity and knowledge.

Throughout the film, the telephone is thus presented as potentially dangerous to the reining social order. Working as promulgator of monstrously fluid and unstable identities, it provides the threat of difference upon which the film's idealization of rigid identity positions rests, and which the film can then use to place the viewer in a position of anxiety ostensibly making him or her susceptible to ideological interpellation. In other words, coding fluid and unstable identities as dangerous, is a central step in the film's attempted enforcement of established and socially acceptable categories of identity. Even while presenting the telephone and its powers of diffusion and disembodiment as a device for the production of dangerous difference, however, the film cannot escape returning to and consistently foregrounding the telephone's many resemblances to cinema. As detailed in this article, Black Christmas implicitly establishes a remarkable pattern of resemblance between the telephonic and cinematic mediums. If the telephone's powers of diffusion and disembodiment make it a danger to the established social and political order, it seems that cinema belongs in that category of dangerous cultural forces as well. Indeed, insofar as cinema allows identities to become fluid and malleable, that is, insofar as it is itself an engine of monstrous difference, cinema is itself a threat to the ideological structures that the film attempts to impose.

The telephonic motif in Black Christmas is, thus, a focal point for the film's implicit engagement with cinema itself and with the question of its possible cultural and political impact. Even as it attempts to employ the ideological machinery of cinema to enforce normative categories of knowledge and identity, the film simultaneously dwells implicitly upon the capacity of cinema to disrupt and destabilize such categories. In consequence, the telephonic motif in Black Christmas can be understood both as a cipher for the promulgation of ideology through representation and as a possible path beyond it. 


\section{References}

Adams, Ross Exo. 2011. Foreground, Background, Drama: The Cinematic Space of Le Mépris. Critical Quarterly vol. 53, no. 1: 14-28.

Bohnenkamp, Björn. 2014. "You can get anything you want." Telefonie im Film. In Medienreflexion im Film. Ein Handbuch [Mediareflections in Film. A Handbook], eds. Kay Kirchman and Hens Ruchatz, 349-365. Bielefield: Transcript Verlag.

Boillat, Alain: 2015. The Social Imaginary of the Telephone. Fictional Dispositives in Albert Robida's Le Vingtième Siècle and the Archeology of "Talking Cinema." In Cine-Dispositives. Essays in Epistemology across Media, eds. Franois Albera and Maria Tortajada, 217-247. Amsterdam: Amsterdam University Press.

Bruhm, Steven. 2011: Cell Phones from Hell. The South Atlantic Quarterly vol. 110, no. 3: 601-620.

Chion, Michel. 1999 [1982]. The Voice in Cinema, ed. Claudia Gorbman. New York: Columbia University Press.

Clover, Carol J. 1992. Men, Women, and Chain Saws. Gender in the Modern Horror Film. New Jersey: Princeton University Press.

Conner, Steven. 2000. Dumbstruck. A Cultural History of Ventriloquism. Oxford: Oxford University Press.

Danielson, Larry. 1996. Folklore and Film: Some Thoughts on Baughman Z500599. In Contemporary Legend. A Reader, eds. Gillian Bennet and Paul Smith, 55-67. New York: Garland Publishing Inc.

Debatin, Bernhard and Hans Jürgen Wullf. 1991. Telefon und Kultur. Das Telefon im Spielfilm. [Telephone and Culture. The Telephone in Fiction Films], Berlin: Volker Spiess.

Dika, Vera. 1990. Games of Terror. Halloween, Friday the 13th, and the Films of the Stalker Cycle. Rutherford: Associated University Press.

Gunning, Tom. 2004. Fritz Lang Calling: The Telephone and the Circuits of Modernity. In Allegories of Communication. Intermedial Concerns from Cinema to the Digital, eds. John Fullerton and Jan Olsson, 19-37. Rome: John Libbey Publishing.

Gunning, Tom. 1991. Heard over the phone: The Lonely Villa and the de Lorde Tradition of the Terrors of Technology. Screen vol. 32, no. 2: 184-196.

Hart, Adam Charles. 2020. Monstrous Forms. Moving Image Horror across Media. New York: Oxford University Press. 
Nowell, Richard. 2001. Blood Money. A History of the First Teen Slasher Film Cycle. New York: Continuum.

Olsson, Jan. 2004. Framing Silent Calls: Coming to Cinematographic Terms with Telephony. In Allegories of Communication. Intermedial Concerns from Cinema to the Digital, eds. John Fullerton and Jan Olsson, 157-192. Rome: John Libbey Publishing.

Riser, Klaus. 2001. Masculinity and Monstrosity: Characterization and Identification in the Slasher Film. Men \& Masculinities vol. 3, no. 4: 370-392.

Schantz, Ned. 2008. Gossip, Letters, Phones: The Scandal of Female Networks in Film and Literature. Oxford: Oxford University Press.

Schantz, Ned. 2003. Telephonic Film. Film Quarterly vol. 56, no. 4: 23-35.

Wagner, Hedwig. 2014. "Leave your conscious after the beep." Der Anrufbeantworter im Film [The Answering Machine in Films]. In Medienreflexion im Film. Ein Handbuch [Mediareflections in Film. A Handbook], eds. Kay Kirchman and Hens Ruchatz, 367-382. Bielefield: Transcript Verlag. 